\title{
El tejido del cosmos. Tiempo, espacio y arte de la hamaca entre los ette (chimila)
}

L'étoffe du cosmos. Espace, temps et art du hamac chez les Ette (Chimila)

The cosmic textile. Space, time and hammock art among the Ette (Chimila)

\section{Juan Camilo Niño Vargas}

\section{OpenEdition}

\section{Journals}

Edición electrónica

URL: https://journals.openedition.org/jsa/13726

DOI: $10.4000 /$ jsa. 13726

ISSN: $1957-7842$

Editor

Société des américanistes

Edición impresa

Fecha de publicación: 17 septiembre 2014

Paginación: 101-130

ISSN: 0037-9174

Referencia electrónica

Juan Camilo Niño Vargas, «El tejido del cosmos. Tiempo, espacio y arte de la hamaca entre los ette (chimila)», Journal de la Société des américanistes [En línea], 100-1 | 2014, Publicado el 01 enero 2016, consultado el 03 septiembre 2022. URL: http://journals.openedition.org/jsa/13726 ; DOl: https:// doi.org/10.4000/jsa. 13726 


\title{
EL TEJIDO DEL COSMOS. \\ TIEMPO, ESPACIO Y ARTE DE LA HAMACA ENTRE LOS ETTE (CHIMILA)
}

\author{
Juan Camilo NIÑO VARGAS *
}

\begin{abstract}
Mediante un examen de las correspondencias observadas entre principios cosmológicos y cultura material, en el presente artículo se propone un modelo del universo ette, pueblo de lengua chibcha del norte de Colombia. Se compara la forma en la que se experimenta el espacio y el tiempo a nivel cósmico con la manera en la que se concibe y se usa la hamaca. Se expone el modo en que este objeto parece materializar un complejo conjunto de nociones sobre el universo: desde la forma cóncava, bipolar e inestable de la tierra, hasta la tripartición entre un presente humano ligado al medio, un pasado animal vinculado a lo bajo y, por fin, un futuro divino asociado a lo alto. [Palabras claves: cosmología, espacio, tiempo, hamaca, tejido, ette, chimila.]
\end{abstract}

L'étoffe du cosmos. Espace, temps et art du hamac chez les Ette (Chimila). À travers un examen des correspondances entre principes cosmologiques et culture matérielle, l'article propose un modèle du monde ette, peuple de langue chibcha du Nord de la Colombie. On compare la façon dont l'espace et le temps cosmiques sont vécus avec la manière dont les Indiens conçoivent et utilisent le hamac. On montre comment cet objet matérialise un ensemble complexe de notions concernant l'univers, allant de la forme concave, bipolaire et instable de la terre, à la tripartition entre un présent humain rattaché au centre, un passé animal lié au bas et, enfin, un futur divin associé au haut. [Mots-clés: cosmologie, espace, temps, hamac, tissu, Ette, Chimila.]

The cosmic textile. Space, time and hammock art among the Ette (Chimila). The aim of this article is to put forward a model of the Ette universe, a Chibchan speaking people of northern Colombia, through an analysis of the relationship between cosmological principles and material culture. The way in which time and space are experienced at a cosmological level is compared with conceptions of the hammock and the way it is used. We show how this object materializes a complex set of cosmic notions: from the concave, bipolar and instable shape of the earth, to the tripartition between a human present located in the middle, an animal past placed below and, finally, a divine future situated above. [Key words: cosmology, space, time, woven textile, hammock, Ette, Chimila.]

* Laboratoire d'anthropologie sociale, Paris; Universidad de los Andes, Bogotá [juancamilonino@gmail.com].

Journal de la Société des Américanistes, 2014, 100-1, pp. 101-130. ㅇ Société des Américanistes. 
Threads may be transformed into traces, and traces into threads. It is through the transformation of threads into traces, I argue, that surfaces are brought into being.

Los hilos pueden transformarse en trazos, así como los trazos en hilos. Es a través de la transformación de hilos en trazos, arguyo, que las superficies adquieren existencia (Ingold 2007, p. 52 [traducción del autor, J. C. N. V.])

« La tierra, aquella por la que andamos, es ancha », afirman los ette. Puesto que proviene de un pueblo establecido en las vastas planicies del norte de Colombia, semejante afirmación no parecería exigir ninguna explicación. Sin embargo, al referirse al mundo de tal manera, los ette hacen algo más que ofrecer una simple descripción topográfica. De manera directa también lo relacionan con un conjunto de elementos dentro de los cuales la hamaca es un objeto prototípico.

Partiendo de tal asociación, y sobre la base de información recogida durante un trabajo de campo extenso, en el presente artículo se propone un modelo del mundo ette ${ }^{1}$. Para esto se compara la manera en la que se experimenta el espacio y el tiempo a nivel cósmico con el proceso de confección, la morfología y el uso de la hamaca. Se expone el modo en que este objeto parece materializar un complejo conjunto de nociones sobre el universo: desde la forma cóncava, bipolar e inestable de la tierra, hasta una concepción del devenir en la que un tiempo humano presente se opone por igual a un pasado animal vinculado con lo bajo y un futuro divino asociado a lo alto. El análisis aprovecha las correspondencias entre cosmos y hamaca para reconstituir recíprocamente sus propiedades y, simultáneamente, restablecer el modelo general que les sirve de base. De esta suerte, se pretende avanzar por el mismo camino que ha conducido a otros autores a formular modelos no euclidianos de los universos amerindios (Daillant 2003, pp. 419-453; Hugh-Jones 1979, pp. 235-274; Surrallés 2003, pp. 89-110).

Paralelamente, se espera contribuir al conocimiento de un objeto omnipresente en la vida de muchos pueblos indígenas, pero cuya dimensión social poco ha despertado el interés de la antropología. En efecto, aunque en las etnografías suelen aparecer algunas cortas notas sobre los usos y significados de la hamaca, prácticamente todas las investigaciones consagradas a su estudio se han concentrado en sus aspectos técnicos (por ej. Littlefield 1976; Wiedemann 1979) y sólo desde una época reciente se ha explorado su importancia cosmológica (Seiler-Baldinger 1979; Walker 2009). 


\section{Los ette del norte de Colombia}

El etnónimo chimila es común en la literatura histórica y etnográfica pero el pueblo al que denota prefiere llamarse « ette », literalmente " gente ». Su actitud no es arbitraria si se tiene en cuenta que el nombre «chimila » fue objeto de manipulación política durante el periodo colonial y no corresponde a ninguna forma de autodenominación nativa contemporánea (Niño Vargas 2007, pp. 2566). Además, como se expondrá más adelante, los ette se consideran a sí mismos un pueblo nuevo y completamente diferente de aquellos que otrora habitaron su territorio, identificados como los verdaderos « chimila ».

Los ette ocupan las llanuras que se extienden entre las estribaciones suroccidentales de la Sierra Nevada de Santa Marta y los ríos Cesar y Magdalena, en el norte de Colombia. La mayor parte de la población está establecida en un resguardo creado en la década de 1980 compuesto por dos grandes propiedades: Issa Oristunna y Ette Butteriya, en el municipio de Sabanas de San Ángel. A esto hay que agregar otros dos pequeños asentamientos de reciente origen: Narakajmanta e Itti Takke, en la base del macizo serrano (Figura 1). Entre todos albergan unas 1200 personas y a esto hay que sumar pequeños grupos que residen en pueblos vecinos.

La mayoría de los especialistas concuerdan en que su lengua pertenece a la familia chibcha (Trillos Amaya 1996; Malone 1997) ${ }^{2}$. Su cultura, de franca orientación igualitaria, pareciera tener rasgos en común con la de los grupos de las tierras bajas sudamericanas. Aunque la caza y la guerra fueron actividades importantes hasta el siglo pasado, hoy en día la mayoría se dedica a la agricultura $\mathrm{y}$, debido a las relaciones de explotación entabladas con la sociedad nacional, al trabajo asalariado en haciendas ganaderas.

\section{Principios de cosmología}

A continuación se exponen ciertas nociones cosmológicas compartidas por la mayoría de los ette. El objetivo no es inventariar exhaustivamente sus concepciones sobre el universo sino, más bien, identificar algunos de los principios básicos que las fundan. Para esto, se describen las diferentes regiones que componen el cosmos; se exponen los principales rasgos que caracterizan el mundo humano; y, por fin, se examina la forma en la que el universo se transforma con el paso del tiempo.

\section{La estructura del cosmos}

Al igual que otros pueblos amerindios, los ette consideran que el cosmos está compuesto por un número finito de regiones contiguas. Aunque no existe un 


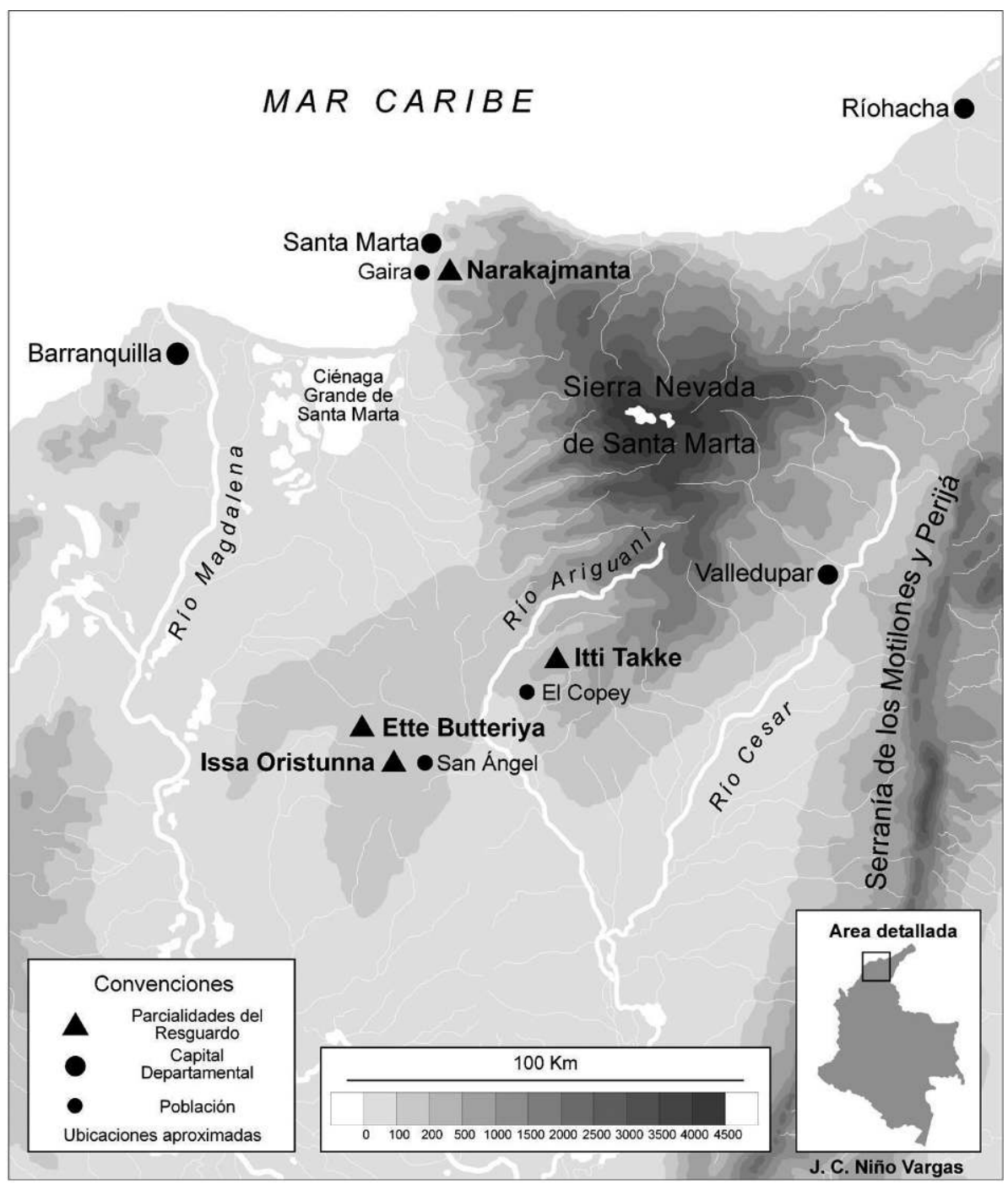

FIG. 1 - Resguardos ette.

término nativo para referirse al conjunto global que conforman, ni poseen nombres propios y precisos, se distinguen por la posición superior o inferior que ocupan respecto a un mundo central humano. Los ette habitan esta área intermedia, descrita por medio del vocablo itti, con el que también se designa a la tierra. 
Los ette afirman que en la actualidad existen por lo menos dos mundos aparte del propio, cada uno con sus respectivos habitantes. El primero está localizado en la bóveda celeste, en un elevado paraje al que se refieren con deícticos espaciales pero al que ocasionalmente también llaman itta, una expresión usada para designar al cielo. El mundo celeste no difiere considerablemente del intermedio. Los seres que lo habitan se conciben como humanos aunque libres de cualquier mal corporal, incluidas la enfermedad y la muerte. Asimismo disfrutan de la luz del sol, astro que surge de las estribaciones surorientales de la Sierra Nevada y se esconde en las llanuras occidentales para, enseguida, iluminar la región superior recorriendo su firmamento en sentido inverso. El otro mundo, se encuentra en las profundidades de la tierra. A diferencia de las otras dos regiones, no participa del ciclo solar, siendo una región oscura, llena de agua y poblada por criaturas monstruosas (Figura 2).

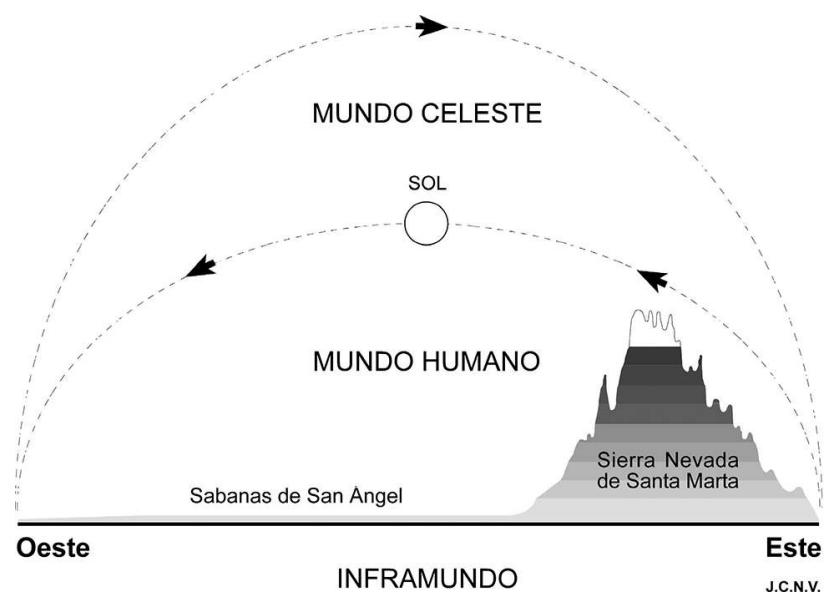

FIG. 2 - Estructura del cosmos.

Semejante organización de lo existente hace que la comunicación entre uno y otro nivel del universo sea restringida y que la vida se desarrolle en cada uno con bastante independencia. Aunque la forma en la que este conjunto permanece firme es fuente de debates, prácticamente todos los indígenas coinciden en afirmar que es por obra de los ancianos, quienes con sus oraciones impiden que el cielo se desplome. Para la expresión de esta idea utilizan el verbo grooga'a, que puede traducirse como "sostener» o "respaldar». Esta locución está emparentada con otras formas verbales como grookwa, " resistir », y grootikaa « sentirse respaldado o protegido ». 


\section{Morfología del mundo humano}

Rara vez los ette se detienen a discutir sobre la forma del mundo humano. Antes que una entidad representable sobre la cual se posea un conjunto transmisible de nociones integradas, la tierra es una realidad vivida. Se conoce en la misma medida en la que se recorre, hecho por el cual también la denominan con locuciones como tagkre yukke: "aquella por la que andamos». A esto hay que sumar que el sentido de territorialidad ette es laxo si se compara con el de sus vecinos de la Sierra Nevada y la Guajira. Entre sus diversas expresiones se encuentran un escaso desarrollo de la noción de dominio sobre los espacios continuos, un corto inventario de topónimos, una geografía sagrada relativamente simple y una marcada inclinación a tomar como referentes espaciales objetos perecederos como casas, cultivos y árboles.

De ahí el valor de la siguiente narración, brindada por un respetado anciano, en la que aparecen condensados muchos de los principales rasgos que los ette le atribuyen a la tierra.

Ette itti - La tierra ette

Narrador: Joaquin Masias Jiintiyu'

Ette Butteriya, 2011

\section{Ette}

1 ¿Amatati sakka'owaya keeragotakwagedanura naarira inni?

2 ¿Amatati jattiragedaka?

3 Samanagkre migkisalagenta wi niiya

4 Aarinarate ette itti, niiya nagkre

5 Aarinarate ette itti nura naarira negwa inni

6 ¿Kiiyamane gooka inni?

7 ¿Kiiyamane keeragotaga?

8 Samane wimetuu inniki tane ette'eni

9 Innikimata katte katemata, katte kateka

10 Inni ettana kora taarakwa

11 Etta maanabre nowe diitake breekrinibre

12 Ettane sakka'owaya keeragota

13 Oo tewe yake kogkrakragga'

14 Oo tewe yake kogkrakraggatikkwi

15 Ni kolla taata chorida'

16 Ettane sakka'owayaneti keeragowita nara Yaau

17 Etta maana koggowakkani, ni akki ni Yaau

\section{Español}

¿No fue a propósito que se delimitó este lugar para nosotros?

¿Acaso no fue así?

Así fue y por eso sabemos cómo empezó

Nosotros decimos que ésta es nuestra tierra

Es nuestra tierra, es para nosotros que estamos acá

¿Por qué fue hecha acá?

¿Por qué la delimitaron?

Para que pudiera saberse que era tierra ette Acá adentro la tierra es plana y extensa Justo acá, donde ahora hablo

Por donde pasan esas aguas explayadas En donde se delimitó premeditadamente

Pero no por los arroyos

Ni por las cañadas

Sino por la verdadera madre antigua

Este lugar fue definido intencionalmente por nuestro Padre

Por donde pasa el profundo arroyo, el patio del Padre 
18 Samane wimetuu ta ette'eni inniki katte kateka

19 Dussawa, diitake buttanare ni'naniki aarite ejkoograte'ye'

20 Inniki nara eekera'ye katte kateka

21 Diwannaniki, lakkrakikkra buttanare tane kora ejkoograte'yeni

22 Yaau kora koograte'yeni kora, kora tewati anta kora

23 Tamine eekera'ye nara

24 Nara eekera'ye tane sakka'owaya keeragota

25 Samane wimetuu nara itti eekera'ye innikimata

26 Innikimata katte kateka

27 Inni jukkrusa, ni too nara itti'

28 Jannayorikra nii dekkwi nagkre ette
Para que pudiera saberse que las tierras extensas eran de los ette

El occidente, la otra orilla de las aguas, es de otra gente

Acá, en donde la tierra es extensa, es nuestro

El oriente, el otro lado de la columna

vertebral, es de otra gente

$\mathrm{Y}$ esa gente tiene su propio padre, son

diferentes

No es nuestro

Lo nuestro es lo que fue delimitado a propósito

Para que se reconociera nuestra tierra acá adentro

Acá adentro la tierra es extensa

Este es el medio, es el corazón de la tierra

Nosotros los ette lo llamamos Jannayorikra

Una excepción a la reticencia de pronunciarse sobre la tierra es la afirmación, aparentemente obvia, que resalta su inmensidad. Para la expresión de esta idea, el narrador se vale del radical $k a$-, un clasificador lingüístico que encierra la idea de extensión (Narración líneas 9, 20 y 26). Con él construye adjetivos como katte katemata o katte kateka, traducidos al español regional como "plano » y " grande ». Otros ette usan el vocablo $k a^{\prime} y e$ : « ancho ». El mundo vista como una gran planicie coincide con el territorio en donde residen los indígenas: una vasta llanura de pendientes poco pronunciadas en la que el horizonte oriental, si la vegetación lo permite, sólo se ve interrumpido en la lejanía por las estribaciones meridionales de la Sierra Nevada de Santa Marta.

La extensión del mundo humano tiene un carácter preciso. La tierra no se piensa como un plano homogéneo. Por el contrario, parece concebirse como una superficie explayada entre dos polos que coinciden con los puntos por los que sol aparece y desaparece. Y es que si existe un eje que estructura el espacio, condiciona la percepción de los fenómenos que ocurren en él y determina el ordenamiento de los seres que lo habitan, es aquel formado por el levante y el poniente (Narración, líneas 19-21). De oriente a occidente se desplazan el sol, la luna y las constelaciones que marcan los ritmos temporales, así como los vientos y las tormentas que anuncian las estaciones. El caballete que sostiene el techo de las casas, la morada de los seres sobrenaturales y los caminos que recorren las almas de los muertos se orientan sobre el mismo eje. Además, cada extremo se asocia a un sexo, de tal forma que una amplia gama de actividades, desde agrícolas hasta lúdicas, tienen una expresión diametral: siempre el género masculino al este y el femenino al oeste. 
La bipolarización del cosmos se refleja claramente en el sistema de coordenadas. Como es frecuente en las tierras bajas sudamericanas, los únicos puntos cardinales reconocidos son el levante y el poniente (Daillant 2003, pp. 427-434; Surrallés 2003, p. 96; Queixalos 1985, pp. 124-127). El primero se designa diwanna, vocablo emparentado con aquellos que expresan la idea de claridad; el segundo se denomina dussawa, locución que remite al ocaso. Un tercer término podría agregarse, tijbrakenta, pero, estrictamente hablando, no designa ningún punto sobre la tierra. A lo que esta expresión se refiere es, más bien, a una dirección transversal respecto al eje este-oeste, hecho por el cual los ette la traducen espontáneamente como « atravesado » (Figura 3). El norte y el sur, puntos cardinales tan familiares para las culturas andinas y europeas, no tienen ningún sentido, ni se marcan lingüísticamente, por lo que su eje queda subordinado al que forman el este y el oeste. La importancia de la bipolarización es tal que muchos verbos de la lengua ette expresan con exactitud la orientación de la acción denotada, ya sea implícitamente o por su asociación a cierta clase de partículas. Así se distingue moota, "conducir a alguien hacia oriente ", de mookaga, " conducir a alguien hacía occidente »; o también, tunnukwa, " mirar hacía el saliente », y tugkaga, « mirar al poniente ». Los ejemplos podrían multiplicarse.

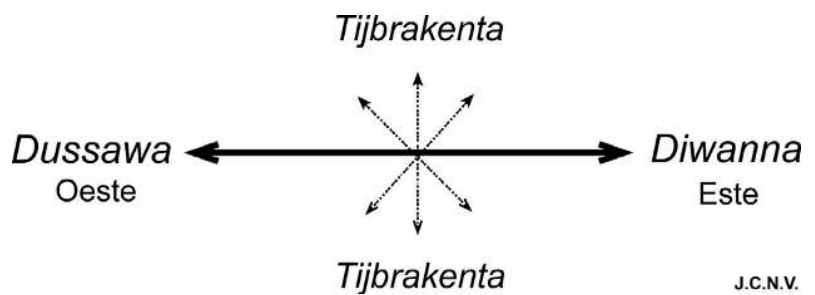

FIG. 3 - Puntos cardinales.

La idea de una extensa superficie estructurada sobre un único eje bipolar no implica la imposibilidad de señalar un sector central y unos confines (Narración, líneas 9-20, 27-28). Los ette son enfáticos al respecto. Inni jukkrusa, ni too nara $i t t i$, «Aquí es el centro, el corazón de nuestra tierra », afirma el narrador refiriéndose a Jannayorikra: la región de Sabanas de San Ángel, un área que abriga la mayor parte de la población indígena.

La localización de Sabanas de San Ángel también remite a un área interior y contenida, opuesta a unos sectores exteriores y contenedores (Narración, línea 27). Un examen de los tres localizadores usualmente empleados por los indígenas para situar su territorio aclara esta concepción. El término más utilizado es jukkru, asociado a la idea de un puesto " intermedio » y opuesto a las posiciones de « adelante », chotta, y « atrás », brikki. Este mismo vocablo, además, se usa para designar el duramen, esto es, la parte interior, seca y dura de los troncos de 
ciertos árboles. Una segunda expresión es tiñ̃a, vinculada a la idea de « adentro », « en medio » $\mathrm{y}$ « fondo » $\mathrm{y}$, en esa medida, contraria a laaniki, «afuera ». El tercer término, usado cuando el hablante quiere darle a su afirmación un giro retórico, es too, con el que también se designa al corazón y al alma humana, ambos localizados en el interior de la caja torácica.

Los límites del mundo ette están señalados por el mar y los ríos Magdalena y Cesar. En realidad, los tres se consideran un sólo cuerpo de agua que rodea la tierra, amenazándola con inundarla y recorriéndola sin fin en sentido dextrógiro. Las aguas del Cesar descienden hasta el Magdalena para continuar hacía el Mar Caribe, atravesar por detrás la Sierra Nevada y reiniciar el ciclo (Figuras 1 y 4). Dentro de las muchas expresiones que se emplean para denominar esta inmensa corriente de agua, se encuentran koggowakka, "arroyo profundo », y diitake breekinibre, « agua explayada ». Otra, quizá más interesante, es akki ni Yaau, « el patio del Padre », expresión que proyecta a escala cósmica la idea de una zona limítrofe entre la casa y el rastrojo o, lo que es lo mismo, entre un espacio doméstico y un espacio inculto. Por su parte, el narrador del relato transcrito optó por la originalidad y acuñó una expresión desconocida por la mayoría de los indígenas, pero cuyo significado era claro en el contexto de la enunciación: taata chorida, literalmente, « madre antigua » (Narración, línea 15).

En armonía con esta serie de ideas, los indígenas utilizan el verbo keerago para hablar de su territorio. Valiéndose del español regional, algunos lo traducen como " encercar » o " lindar », expresiones que esconden la idea de "crear un espacio interior » (Narración, líneas 1, 7, 12, 16, 24). En esa medida, se emplea para referirse a un conjunto diverso de acciones que abarcan la edificación de los muros de una casa, la construcción de corrales y, entre otras, la elaboración del entretejido de la hamaca. En el contexto de las discusiones cosmológicas, se usa para afirmar que el mundo habitado por los ette es el resultado de una acción, a saber, la de la creación de un espacio habitable, diferenciado, interior y resguardado. Delimitada por las aguas de los ríos y las alturas de la Sierra, la tierra es un continente: contiene a los humanos.

Un último rasgo del mundo humano es el de un ligero antropomorfismo. Los ette identifican la tierra con el torso de una enorme mujer. Los nombres que recibe están invariablemente compuestos por términos de parentesco: yuunari kraari, "gran abuela », y kajmanta, "madre ». Aunque las correspondencias entre las partes del cuerpo de la gran mujer y los accidentes geográficos del territorio son sumamente escasas, existe una notable excepción. Ésta consiste en reconocer en la Sierra Nevada la columna vertebral de la madre tierra (Narración, línea 21). En efecto, el macizo serrano se distingue con la locución lakkrakikkra, "columna vertebral ». Lejos de ser un eje divisor, este colosal espinazo se encuentra en un extremo, proyectándose desde el oriente hacía el nororiente y figurando como límite entre el territorio ette y el de los grupos serranos (Figura 4) ${ }^{3}$. 


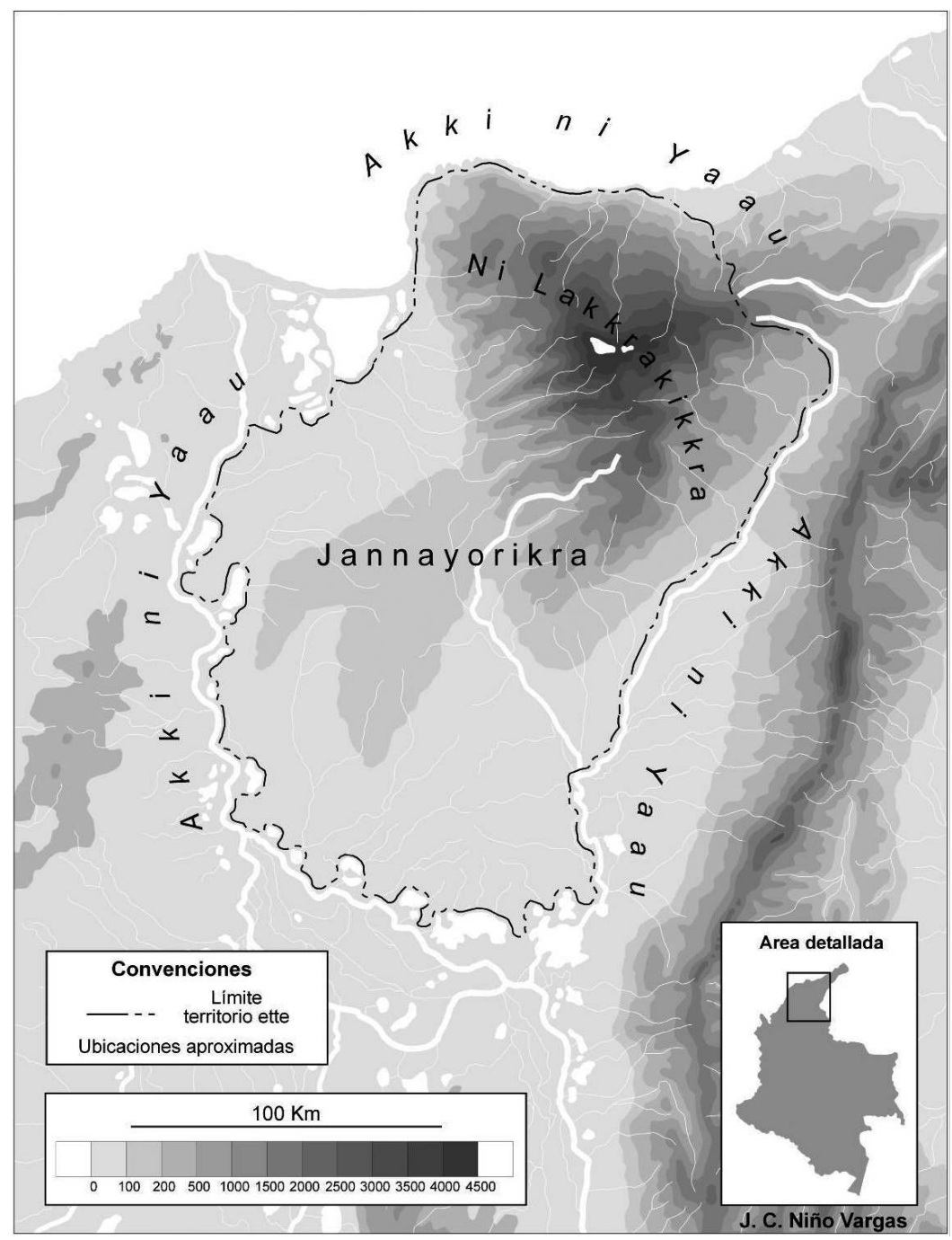

FIG. 4 - El mundo ette.

\section{La dinámica cósmica}

La idea de un mundo humano encajonado entre varias regiones cósmicas es una noción bien presente en el mundo chibcha (Reichel-Dolmatoff 1985, vol. 1, pp. 225-227; Morales Gómez 1993, p. 173; Osborn 1995, pp. 73-75). La singularidad del pensamiento ette radica en que le otorga un dinamismo único a tal organización. La configuración actual de lo existente no es más que un 
estado transitorio dentro de un proceso continuo de cambio. No siempre el mundo humano ha ocupado una posición intermedia, ni el conjunto de los seres vivientes ha estado organizado en tres regiones superpuestas. La estructura del universo cambia periódicamente por obra de catástrofes que destruyen regiones completas y aniquilan a todos sus habitantes pero que, también, permiten el surgimiento de nuevas humanidades ${ }^{4}$.

El movimiento de transformación cósmica es descendente. Pese a que son muy pocos los informes que pueden recogerse sobre la forma primitiva del universo, algunos ette aseguran que tuvo que estar compuesto por el mundo subterráneo, una tierra intermedia y varias regiones celestes contiguas. Las capas superiores fueron derrumbándose una por una sobre la tierra, sepultando a la humanidad que en ese momento residía en ella y permitiéndole al pueblo recién llegado llevar una vida normal durante cierto tiempo. El mundo de los ette y la actual organización tripartita del cosmos son, así, el resultado de una serie de desastres que sólo concluirán una vez el último cielo se desplome. A diferencia de las demás tierras, el inframundo permanece estable y no entra a formar parte activa del gran proceso.

Los ette consideran imposible que alguien sepa con exactitud lo que aconteció durante los primeros ciclos destructivos. Los cataclismos borraron cualquier rastro de los antiguos mundos, reduciendo a ruinas los logros de las civilizaciones que los poblaron. Algo diferente ocurre con el proceso que le otorgó al universo su aspecto actual. Varios mitos cuentan cómo tiempo atrás la tierra estaba habitada por dos belicosos pueblos: los ette chorida, «la gente vieja » o " chimilas », y sus enemigos los waacha chorida, « los blancos viejos » o " españoles ». La dureza con la que describen los enfrentamientos entre estos dos grupos sólo es comparable con los crudos testimonios que se encuentran en los documentos del siglo XVIII. Los combates armados, la captura de prisioneros y la destrucción de poblados son temas que aparecen a menudo en ambas tipos de fuentes (Herrera Ángel 2002, pp. 265-286; Uribe Tobón 1977). Semejante estado de cosas enfureció a las divinidades, quienes se encargaron de acabar la violencia terrenal mediante incendios y diluvios. El destino que se reservó a los chimilas fue el de perecer bajo el lodo y las cenizas o, en su defecto, ser convertidos en fieras y animales.

Pero para el pensamiento ette los procesos de degradación son inseparables de los de regeneración. El fuego y el agua que exterminaron a chimilas y españoles también prepararon el advenimiento de una nueva tierra. Sobre el fango dejado por los cataclismos descendió el mundo de los ette. Conformado por los antepasados de los actuales indígenas, este pueblo de origen celeste se autodenominó ette takke, "gente nueva ». Así, hombres nuevos en una tierra nueva, los ette no se consideran un pueblo de orígenes remotos, niegan cualquier tipo de lazo con las poblaciones que otrora ocuparon el área, descartan toda relación entre su cultura y el material arqueológico que se halla en su territorio y rechazan enfáticamente la identificación con los chimila. 
Tagkre yukke naarira itti aarinarate itti takke, « Aquella tierra nuestra por la que andamos es nuestra tierra nueva », afirman los ette con frecuencia. Y usando casi las mismas palabras se expresan sobre su futuro: tagkre yukke naarira itti, yuma nowe naakemekaane, "y esta tierra nuestra por la que andamos no la pisarán ellos ». Lejos de referirse a los chimila, el « ellos » de la última oración designa a los pobladores del cielo, quienes, con el correr del tiempo, reemplazarán definitivamente a los ette. En medio de incendios y diluvios, su tierra descenderá aplastando a la humanidad actual. Con este suceso, el ciclo de cataclismos concluirá y el universo entrará en un estado de pasividad. A diferencia de todos los otros, el nuevo mundo será eterno: los hombres serán inmortales, la violencia estará ausente y no existirán los dolores y las enfermedades asociados a la tenencia de un cuerpo. Aunque los ette nunca se expresan en estos términos, bien podría decirse que este mundo no será uno de gente de carne y hueso sujeta a la corrupción sino, más bien, uno de almas.

Antiguos mitos cuentan cómo las almas de ciertos hombres asesinados se desplazaban al cielo y vivían allí transformadas en gallinazos (Niño Vargas 2007, pp. 313-318). Este episodio establecería una relación entre las almas de los muertos y el pueblo celeste y, dada la dinámica cósmica que acaba de describirse, entre el pasado y el futuro. Sin embargo, tal motivo mítico resulta oscuro para actuales ette y entra en contradicción con las creencias escatológicas aceptadas. Según éstas, las almas de los muertos se retiran a un lugar distante y distinto del cielo para no volver a inmiscuirse en los asuntos humanos.

\section{Aspectos materiales, SOCIALES Y Simbólicos de la HAMACa}

Las descripciones de los aspectos técnicos de la cultura material con las que se inauguró la etnografía americanista cedieron su puesto a estudios centrados en la forma en la que servía de soporte a órdenes sociales y esquemas intelectuales. Este nuevo tipo de aproximación ha sido fecunda en el caso de objetos y oficios como la casa y la arquitectura (Hugh-Jones 1979; Carsten y Hugh-Jones 1995; Karadimas 2005, pp. 369-399); los telares y el tejido (Hall 2012; ReichelDolmatoff 1978; Schaefer 1989); los canastos y la cestería (Guss 1989; Van Velthem 2003); y las armas, la guerra y la caza (Erikson 2001; Rival 1996).

Siguiendo las premisas teóricas de esta serie de trabajos, y con el fin de precisar los principios cosmológicos expuestos en la sección anterior, a continuación se examina un objeto central en la cultura ette: la hamaca. La elección de semejante artefacto tiene justificación. Si desde el punto de vista nativo pertenece a la misma categoría de entidades en la que se ubica el mundo humano, desde el punto de vista del etnógrafo pareciera materializar ciertas concepciones cósmicas. Se examinan cuatro dimensiones: su confección, su morfología, su uso cotidiano y, por fin, su papel en los mitos. 


\section{El proceso de confección}

El proceso de la elaboración de la hamaca ette fue ricamente descrito por la mayoría de los exploradores y etnógrafos que contactaron el grupo durante los siglos XIX y Xx (Brettes 1898, p. 476: Figura 5; Bolinder 1924, p. 211; ReichelDolmatoff 1946, pp. 114-117; Cardale-Schrimpff 1972, pp. 168-172). Las líneas que siguen pretenden complementar esta serie de estudios.

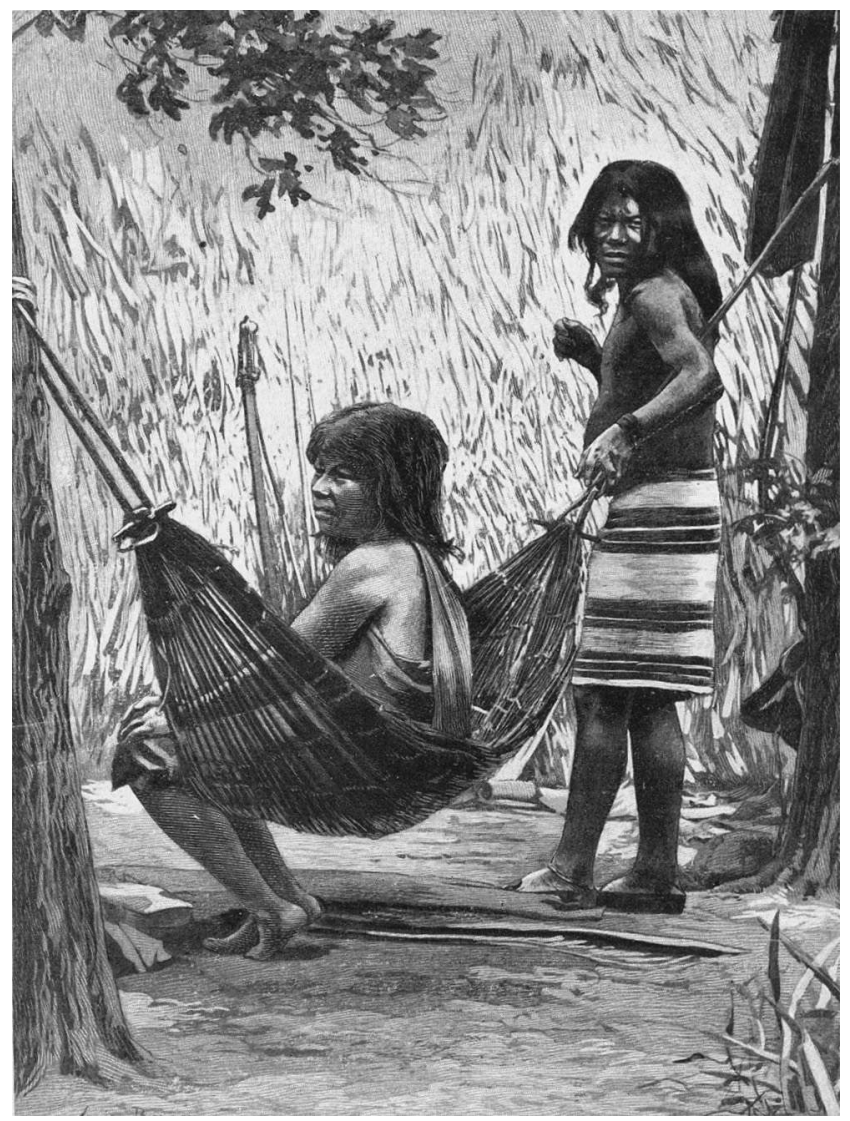

FIG. 5 - La hamaca ette según Joseph de Brettes (1898, p. 476).

De principio a fin, y salvo algunas cortas intervenciones masculinas, la confección de hamacas es un asunto femenino. Son las mujeres quienes siembran, recogen, despepitan e hilan el algodón ${ }^{5}$. La hechura de una hamaca demanda 
dos tipos de hilo. Para la fabricación del primero se enrollan dos hebras en sentido dextrógiro o, como se conoce en la literatura especializada, en " patrón s ». Al igual que todas las demás clases de hilo, los ette suelen denominarlos yoorotiiri, expresión compuesta por el nominal yooro, « algodón », y el adjetivo tiiri, " delgado ». La segunda clase de hilo, mucho más gruesa, se confecciona con tres hebras enrolladas en sentido levógiro o, en jerga especializada, en « patrón z ». Este último recibe un nombre específico, a saber, kuurubru, siendo el único hilo con este grosor. Los contrastes entre los dos patrones de hilado presentan similitudes con los descritos por otros etnógrafos anteriormente, lo que refuerza el carácter no arbitrario de sus respectivos espesores y torsiones (Cardale-Schrimpff 1972, pp. 148-155) ${ }^{6}$.

Una vez finalizado el hilado, dos o más mujeres pueden elaborar una hamaca en unas pocas horas. La técnica empleada es la del entretejido, característica de las barred hammocks (Wiedemann 1979, p. 111; Nordenskiöld 1920, p. 114; Figura 6). Las mujeres le solicitan a un hombre clavar en la tierra dos postes distanciados por un espacio tan grande como el tamaño de la hamaca deseada, que puede oscilar entre 1,5 y 2,3 metros. Una de las participantes, generalmente la mayor y más experimentada, enrolla el hilo delgado en los postes, de abajo hacia arriba, en forma horizontal y teniendo el cuidado de no cruzarlo. La mujer va y vuelve de adelante hacía atrás en lugar de moverse a la redonda, tal y como ocurre en otras regiones de América (O’Neale 1963, p. 128).

A medida que desarrolla esta labor, sus compañeras preparan las tramas cortando varios pedazos de cordel grueso tan largos como dos veces su propia estatura. Los cordeles comienzan a encordarse verticalmente de abajo hacia arriba, ubicando su centro debajo de la última fila inferior de la urdimbre y guardando una distancia entre sí que oscila entre los 15 y los 20 centímetros. Por medio de una torsión que sigue el sentido de las manecillas del reloj, los cordeles reúnen en cada vuelta las mismas dos secciones de hilo enfrentadas a uno y otro lado de los postes (Figura 7). Cuando alcanzan el extremo superior de la estructura, después de haber unido todos los pares de hilos enfrentados de la urdimbre, sus dos puntas se enrollan y atan en la hilera horizontal superior, dándole un aspecto grueso y burdo (Figura 8) ${ }^{7}$.

La urdimbre resultante se comprime y retira de los postes. En cada uno de los bucles de los extremos se inserta y se amarra con hilos de algodón una varita de madera labrada llamada broo. Aunque las mujeres se desenvuelven tan bien como los hombres con el machete, es a éstos a quienes les corresponde la tarea de tallar semejante artefacto. El bastoncito se hace del duramen de ciertos árboles como la lumbre (Handroanthus billbergii) o el dividivi (Caesalpinia coriaria). La hamaca se cuelga introduciendo la varita de madera en cuerdas previamente dispuestas para tal propósito (Figuras 9 y 10). 


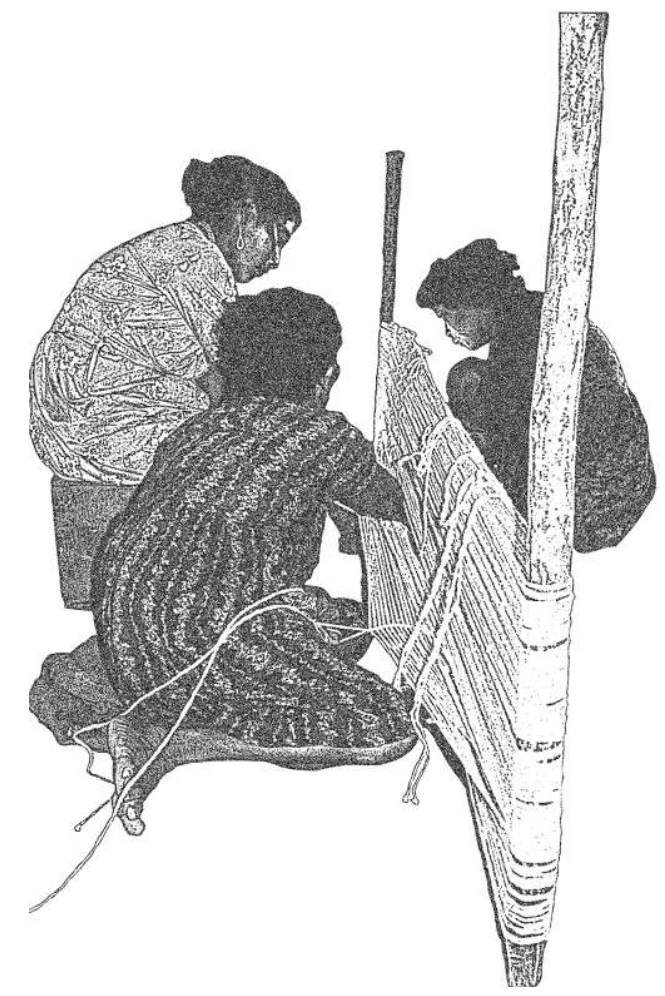

Fig. 6 - Confección de la hamaca ette. Ilustración realizada a partir de una fotografía de Marianne Cardale-Schrimpff tomada en 1968. Cortesía de Marianne Cardale-Schrimpff.
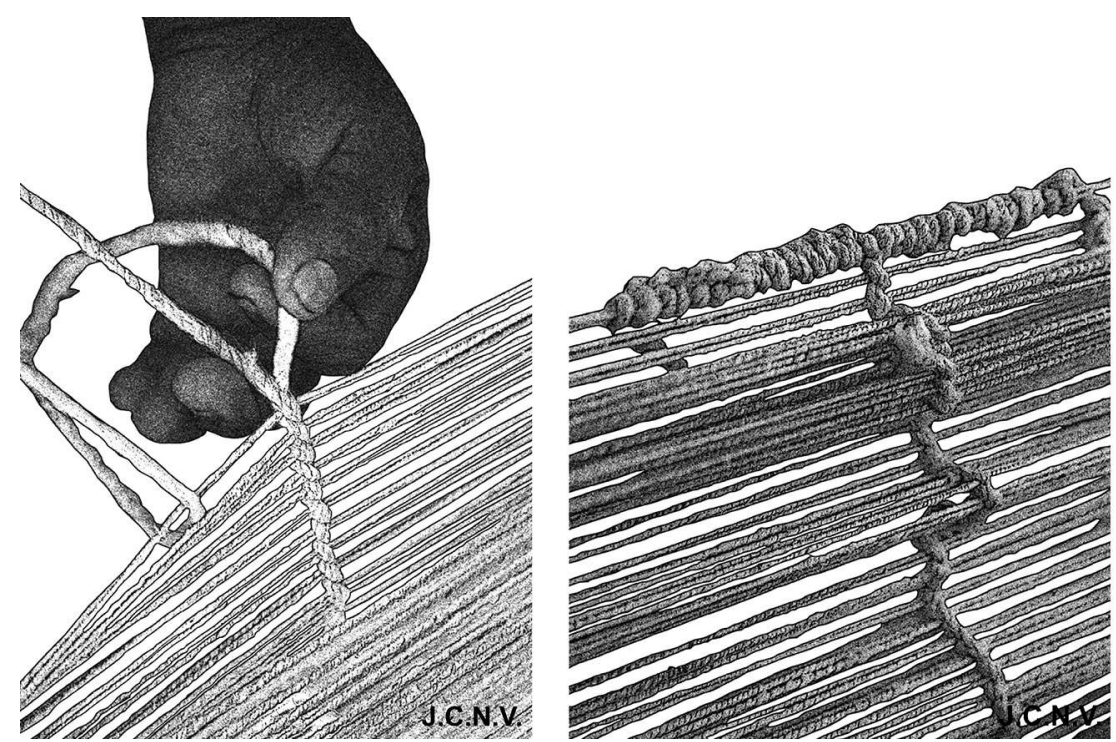

Fig. 7 y 8 - Proceso de entramado y terminación de la trama. 

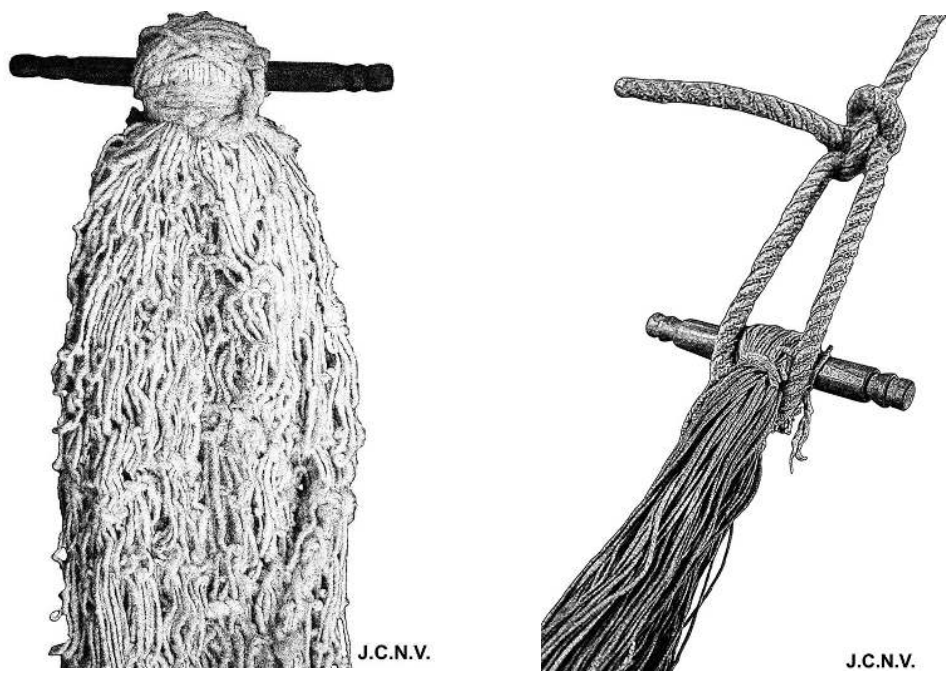

FIG. 9 y 10 - Cabecera de la hamaca y hamaca colgada.

Los bastones de madera que remplazan la cabuyera de las hamacas normales son tan ingeniosos como exóticos. No están presentes en ningún otro grupo del norte de Colombia y, a juzgar por la falta de datos comparativos, no son un patrón difundido en América del Sur. Permiten colgar y descolgar rápidamente las hamacas sin realizar ningún tipo de nudo. Los indígenas pueden desplazarlas con facilidad en función de las cambiantes sombras de los días soleados, o bien del agua que se cuela dentro de las casas por obra de los intempestivos aguaceros de la estación lluviosa.

\section{Anatomía de la hamaca}

Los ette distinguen las entidades y objetos que pueblan el cosmos por las propiedades de sus cuerpos. Las categorías más empleadas son morfológicas, aspecto que se descubre en un sistema de clasificadores lingüísticos presente a nivel numeral, nominal y verbal (Malone 2004; Niño Vargas 2009). La hamaca es uno de los objetos más representativos de una de estas categorías. Descrita con el adjetivo $k a$ 'ye y asociada al clasificador $k a$-, agrupa elementos percibidos como amplios y con la capacidad de contener. Dentro de ellos también se cuentan las mochilas de algodón, las redes de carga, los bancos, las estanterías y las prendas de vestir. Aunque estrictamente hablando no se considera un objeto, el mundo humano hace parte del mismo conjunto. 
La amplitud que los ette atribuyen a estos objetos parece estar asociada a una estructura diametral. En el caso de la hamaca, el entramado de algodón que la conforma se extiende entre dos polos. Mientras que en un primer momento estos coinciden con los postes enterrados de la urdimbre, en una segunda instancia lo hacen con los bastoncitos labrados dispuestos para colgarla (Figuras 6 y 11). Aunque el eje longitudinal que une a los dos polos permanece oculto durante la fabricación, es perfectamente visible una vez la urdimbre ha sido comprimida en sus extremos y todos los hilos delgados convergen en los bastoncitos.

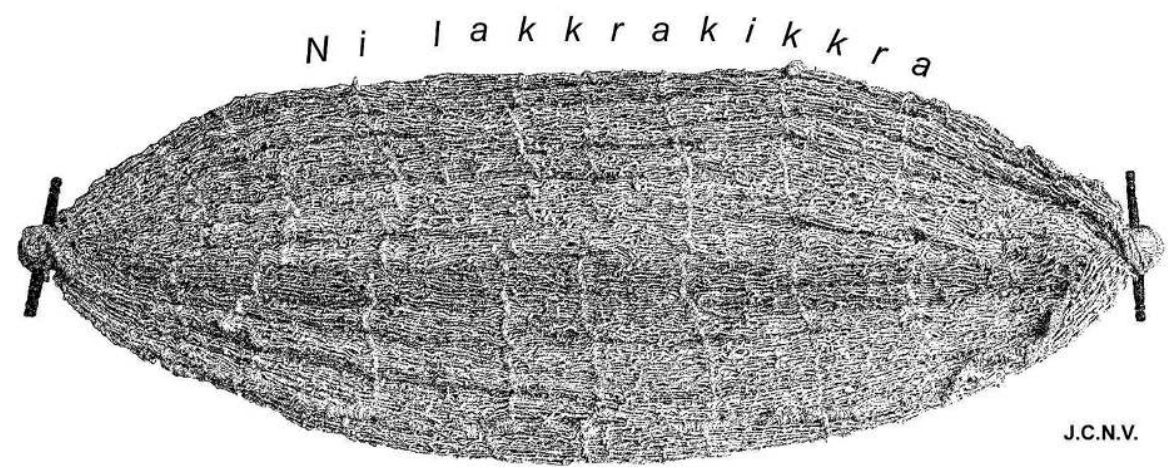

FIG. 11- Anatomía de la hamaca.

Los sentidos de los hilos, la oposición de sus torsiones y su carácter continuo o discontinuo refuerzan la orientación del objeto. Dispuesto longitudinalmente, el hilo delgado de la urdimbre tiene preeminencia. Es la mujer más respetada del grupo la encargada de montarlo entre los postes. Con él forma un esqueleto continuo que nunca se ve fraccionado por cortes o interrumpido por nudos. Además, comparte con toda la cordelería indígena un mismo nombre: yoorotiiri. En franco contraste, el cordel grueso kuurubru que forma la trama ocupa un lugar subordinado. Dando por hecho que se opone a un eje estructural, los ette aseguran que este hilo debe « atravesarse ». Para esto emplean la locución tijbrakenta con la que, como se recordará, también se designa una dirección transversal al eje este-oeste. Son las mujeres jóvenes las encargadas de entretejerlo y su integridad se rompe constantemente por obra de cortes y nudos.

Otro tanto puede decirse del carácter continente de la hamaca. Debido a ciertos detalles de fabricación, este objeto comporta una estructura marcadamente cóncava. Los bastoncitos de madera que suplantan la cabuyera rematan abruptamente sus anchos extremos, otorgándole una forma hueca que algunos observadores han comparado con la de una canoa (Cardale-Shrimpff 1972, 
p. 171). A diferencia de las hamacas de otros grupos indígenas que se aplanan con el peso humano, la de los ette siempre conserva este aspecto hundido (Figura 12). Cada vez que alguien se refiere a la posición que ocupa una persona en ella, utiliza el localizador inesivo -sa, que encierra la idea de « estar adentro » y no, por ejemplo, la de « estar sobre ». A pesar de las apariencias, tal propiedad no parece causarles molestia alguna a los ette, quienes duermen tranquilamente en ellas.

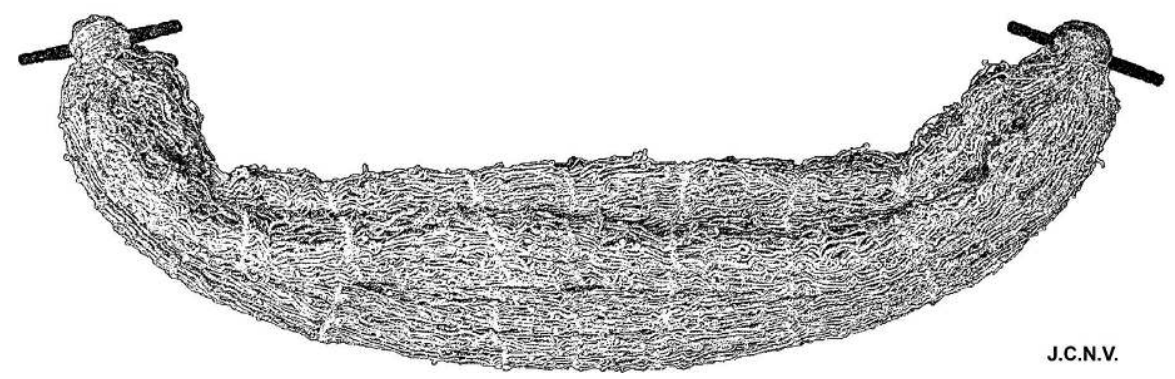

FIG. 12 - La hamaca cóncava.

Otro tanto puede decirse de los bastoncitos que coronan los extremos (Figura 13). Sus puntas escalonadas recuerdan a las de otros objetos. Los mangos de las maracas son de proporciones similares y habitualmente están labrados en forma idéntica en su extremo visible. Los bastones que utilizan los ancianos son más grandes, pero muchos tienen el mismo acabado en su extremo inferior. El motivo incluso puede adivinarse en las piernas de cierto tipo de figurillas humanas de madera utilizadas para orar. Además de ser el fruto del trabajo masculino, todos estos artefactos tienen en común la función de sostener.

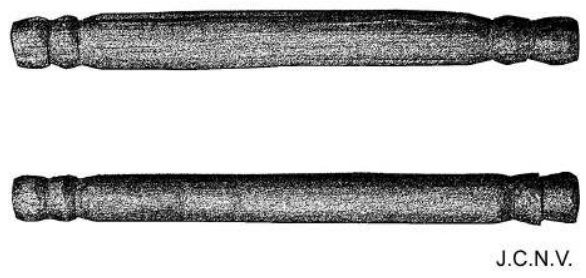

FIG. 13 - Bastoncitos broo.

Ahora bien, estos soportes son introducidos por el bucle de un lazo denominado kraa' (Figura 10). Aparte de designar las cuerdas y las asas de las mochilas, kraa' es un término de parentesco empleado para denotar a un pariente linear de la tercera generación ascendente, esto es, un bisabuelo. Si se parte del 
español, la misma asociación se constata. En efecto, kaawuya es un préstamo del español « cabuya » con que los ette también se refieren a sus bisabuelos. Ante semejante evidencia, es bastante llamativo que un objeto denominado de la misma manera que un pariente linear ascendente sea aquel que abrase a otro en forma de bastón y con todas las características de un soporte. Uno y otro aguantan todo el peso de la hamaca, acción que es descrita con un verbo que ya se ha examinado: grooga' $a$, « sostener » o « respaldar ».

Para terminar, debe examinarse un último rasgo morfológico de la hamaca. Aunque los ette no le atribuyen a este objeto cualidades humanas, sí se refieren a una de sus partes con una expresión reservada para el cuerpo. La última hilera de la urdimbre, más gruesa por causa de las tramas atadas a su alrededor, se identifica con una columna vertebral: lakkrakikkra (Figuras 8 y 11). A diferencia de la humana, que aparece en el principio del proceso de ontogénesis, la de la hamaca representa la conclusión de la labor de fabricación. Sin embargo, ambas cumplen una misma función: la de mantener unida una estructura compuesta por tramas. Ahora bien, tal como acontece con la columna vertebral de la tierra, el espinazo de la hamaca no divide el entramado en dos partes iguales sino, más bien, delimita uno de sus costados. El lado opuesto no recibe ninguna denominación ${ }^{8}$.

\section{La vida social de las hamacas}

Los ette distinguen sus hamacas de aquellas otras de origen industrial que obtienen en los pueblos vecinos, caracterizadas por formas lisas y planas. A las primeras las llaman kissa' o ñaawikra y les tienen reservada la palabra castellana « chinchorro ». Las segundas se denominan jaamaka, préstamo del español « hamaca ». La mayoría sostiene que las hamacas tradicionales son más cómodas y duraderas que las comerciales, pero su número es reducido, hecho que puede explicarse por la facilidad con la que hoy en día se adquieren bienes foráneos. Mientras que a una mujer puede tomarle varias semanas preparar el algodón necesario para tejer una hamaca nativa, un hombre puede comprar una industrial con el dinero ganado en tres días de trabajo en las haciendas.

Tradicionales o comerciales, las hamacas gozan de importancia capital en la vida cotidiana. No son un privilegio reservado a individuos de cierto sexo o edad, siendo compartidas por hombres, mujeres y niños. Aunque su función principal es la de brindar un espacio para el sueño nocturno, también se aprovechan a lo largo del día para sentarse y departir. Los ette afirman que es gracias a ellas que pueden reposar lejos de un suelo húmedo y sobre el cual se desplazan criaturas peligrosas e indeseables. Muchas familias poseen camas rudimentarias de madera, pero ni en importancia ni en número rivalizan con las hamacas. Sin temor a exagerar, puede afirmarse que son el objeto más útil junto a los machetes de hierro y las ollas de aluminio. 
La manera de colgar las hamacas en el interior de la casa obedece en gran medida a cuestiones prácticas como el tamaño de la habitación, el número de huéspedes y el estado de conservación de los postes. Por lo demás, siempre tratan de colocarse de forma ligeramente transversal respecto al caballete del techo que, a su vez, está alineado con el eje este-oeste. Dado que las casas de los ette tienden a presentar una base alargada, esta disposición permite aprovechar mejor el espacio y les garantiza a los individuos guardar cierta armonía con la direccionalidad cósmica. Varias hamacas pueden amarrarse a un mismo poste pero se evita la superposición atando su extremo contrario a párales diferentes. Aunque no se constata ninguna preocupación por la orientación de la última y más gruesa hilera de la urdimbre, la disposición levemente transversal de la hamaca respecto al eje este-oeste hace que, por lo menos en algunas ocasiones, se proyecte del oriente hacia el norte, tal y como lo hace la Sierra Nevada. Cuando esto sucede, las columnas vertebrales de la hamaca y el mundo coinciden.

La hamaca está ligada a todas las etapas de la vida. Los niños se dejan solos en estos objetos, previamente templados y extendidos por medio de dos varas de madera colocadas transversalmente en sus extremos. Asimismo, hasta hace algunas pocas generaciones, los recién nacidos eran transportados en artefactos con una estructura idéntica a la de una hamaca pero dotados de una larga faja continua que la madre se terciaba al hombro. Allí permanecían hasta que las fontanelas de su cráneo se cerraban y su inquieta alma quedaba impedida de escapar y causarles la muerte. El niño se concebía como un alma con un cuerpo incompleto que la pequeña hamaca ayudaba a estabilizar. Este portabebés fue observado tempranamente por Bolinder (1924, p. 223) y aún hoy día se recuerda con claridad. Su nombre en lengua vernácula era sappi o yaasappi, términos que actualmente se emplean para designar a las mochilas.

Los niños duermen en la misma hamaca que su madre o su padre hasta que pueden caminar. Llegado este momento, adquieren una nueva, o bien se ven obligados a desplazarse a las de sus hermanos mayores del mismo sexo. Puesto que están asociadas al bienestar y la prosperidad, al llegar a la adultez la obtención de una hamaca se convierte en prioridad. Mientras que las tradicionales son un signo de la laboriosidad de las mujeres, aquellas compradas lo son del tesón de los hombres en el trabajo asalariado.

En el ocaso de la vida, la hamaca se convierte en mortaja. Los ancianos y los enfermos esperan la hora de la muerte en ella. Una vez sucede el fatídico evento, el cadáver reposa colgado mientras sus familiares planean el entierro. Antes de ser sepultado, el difunto se envuelve en la hamaca con sus posesiones más preciadas. Si los recursos lo permiten, puede depositarse en un ataúd de madera fabricado por los colonos blancos. La cabeza de los hombres reposa en el oeste con sus ojos apuntando hacia el este; inversamente, las mujeres se acomodan mirando hacia el oeste. Si el deceso fue tranquilo, sus almas se dirigirán a estos puntos cardinales para permanecer en un lugar indefinido en los confines del 
mundo. Si, por el contrario, fue trágico uno de sus componentes anímicos permanecerá en la tierra transformado en un agresivo jaguar. Antiguamente, todo adulto se enterraba en el lugar en el que acostumbraba dormir y la casa era abandonada. En la actualidad, la mayoría de las personas se entierran en un sector del resguardo destinado para tal fin, alejado de las casas y completamente invadido de vegetación.

En suma, las hamacas acompañan a un individuo durante más de un tercio de su vida desde que llega al mundo hasta que lo abandona. Siguiendo el ideal de vida ette, un niño permanecerá durante su más tierna infancia en lo alto en una hamaca-portabebés en los hombros de su madre; después se trasladará a una hamaca colgada a una altura media; $y$, por fin, terminará bajo tierra envuelto en aquella en la que dio su último suspiro. El trayecto de uno a otro punto sigue una dirección descendente.

\section{La hamaca en los mitos}

La hamaca aparece con alguna frecuencia en los mitos centrados en la transformación animal. Los relatos pueden agruparse en dos grandes variantes. De un lado, están los que narran cómo las deidades convirtieron en animal a un humano a causa de un comportamiento antisocial. De otro, se encuentran aquellos que relatan cómo una bestia fracasó en su intento de colarse en el mundo de los humanos al ser incapaz de disimular su aspecto por un tiempo prolongado. En las dos variantes, la hamaca figura como un dispositivo gracias al cual la metamorfosis se realiza plenamente.

El primero de los casos es el de Oso Hormiguero, una jovial mujer que solía frecuentar toda clase de fiestas a pesar de estar a cargo de un recién nacido. Otro caso es el de Armadillo, una jovencita a quien el amor por el oficio de hilar algodón la sustrajo de todas las demás obligaciones sociales. Las deidades no vieron con buenos ojos su comportamiento y decidieron convertirlas en animales. Después de recordarles las faltas cometidas, les arrojaron flechas de punta roma y les fumigaron tabaco. Las pobres se revolcaron en sus hamacas, dieron varias vueltas en ellas y cayeron al suelo transformadas, respectivamente, en oso hormiguero (Myrmecophaga tridactyla) y armadillo (Dasypus novemcinctus).

Las historias del segundo tipo están protagonizadas por un jaguar (Panthera onca). Disimulando todos sus rasgos bestiales bajo una figura humana, éste se presenta ante hombres y mujeres que se han quedado solos. En un principio no levanta ninguna sospecha pero, poco a poco, su animalidad se torna evidente. La fiera ronca sin mesura, expele un fétido hedor o demuestra un excesivo temor frente a los perros. Sus compañeros humanos empiezan a desconfiar y esperan a que se duerma para enterar a sus familiares. El gentío llega bien armado, ataca con flechas el bulto que se mece en la hamaca y observa cómo se desploma un felino que corre y desaparece en la selva. 
Las dos variantes presentan motivos similares. El transito de la humanidad a la animalidad sigue un trayecto descendente. Los seres humanos, reales o aparentes, se convierten en fieras al ser empujados al suelo. De caminar erguidos pasan a desplazarse en cuatro patas por efecto de una caída. La pequeña diferencia entre el arriba humano y el abajo animal queda bien marcada por la hamaca, dispositivo transformador que hace las veces de pivote entre uno y otro orden.

\section{SÍNTESIS: UN MODELO DEL ESPACIO Y TIEMPO ETTE}

La recitación de mitos, la celebración de ritos y la discusión de sueños son ocasiones que los ette aprovechan para establecer correspondencias entre niveles aparentemente inconexos: el del mundo animal y el humano, el de la acción ritual y la ordinaria, el de la vigilia y los sueños (Niño Vargas 2006; 2007, pp. 103-210). En contraste, su actitud es mucho más reservada cuando se trata de atribuirle un significado a los objetos que fabrican. Salvo unas contadas excepciones, no se consideran representaciones a escala de otros órdenes, ni existe un saber dedicado a la elucidación de sus rasgos.

Sin embargo, en el caso del mundo y la hamaca las correspondencias existen, siendo muy numerosas y estrechas como para ser fortuitas. Este objeto parece reunir y volver tangibles muchas de las características atribuidas al mundo humano. Inversamente, parecieran ser los principios cosmológicos los que mejor explican las especificidades, aparentemente arbitrarias, de su forma y su uso. Las similitudes más importantes se recapitulan a continuación.

- El mundo humano y la hamaca comparten una serie de rasgos morfológicos que determinan su pertenencia a una misma categoría de objetos. Descritos con la ayuda del clasificador lingüístico $k a$-, estos parecen definirse por una forma amplia y extensa, así como por la facultad de contener. Aunque la comparación podría haberse efectuado con cualquier objeto de esta categoría, la hamaca es tal vez el más representativo del grupo y el más importante en la vida diaria.

- La amplitud que define el mundo humano y la hamaca es bipolar. De un lado, el espacio cósmico se organiza alrededor del eje este-oeste. De otro, la hamaca, desde su fabricación hasta su conclusión, comporta una estructura orientada por un único eje, discernible por la disposición de sus hilos y por los párales que coronan sus extremos. Además, cuando son utilizadas, los ette se esmeran en hacer coincidir el eje de las hamacas con el eje cósmico.

- El mundo se piensa como un continente bien delimitado cuyo centro coincide con un fondo en el que reposan los humanos. Ningún otro objeto ilustra mejor esta serie de nociones que la hamaca. Debido a las particularidades de su fabricación, la hamaca ette se caracteriza por una marcada concavidad en la que 
centro y fondo coinciden. Justamente esta zona central está reservada a los humanos desde el momento del nacimiento hasta mucho después de la muerte.

- El mundo ette se opone a otros dos situados por debajo y encima de él. El superior se asocia a pueblos inmortales semejantes a almas que, encarnando el futuro, habrán de descender al mundo intermedio para sustituir a la actual humanidad; el inferior se relaciona con pueblos sepultados o convertidos en animales que, representando el pasado, habrían sido reemplazados por los ette. Por su parte, la hamaca reposa colgada a una distancia justa entre el suelo y el techo de la casa. Mediando entre el arriba y el abajo, se opone a una hamacaportabebés en la que las mujeres llevan a los recién nacidos en alto; y a una hamaca-mortaja en la que los muertos son depositados bajo el suelo. Ahora bien, mientras que los niños se conciben como almas recién encarnadas que con el tiempo reemplazarán a los adultos, los difuntos se piensan como seres cuya existencia ha concluido y de la cual, en el peor de los casos, sólo queda en la tierra un agresivo componente anímico asociado al jaguar ${ }^{9}$. Así, tanto para la humanidad actual como para los individuos adultos, lo alto se asocia al porvenir y lo bajo a lo que ya ha finalizado, estando ambos puntos unidos por un movimiento descendente. Esta homología entre el orden cósmico y la vida cotidiana queda confirmada por los mitos en los que, justamente, la hamaca marca la diferencia entre una zona media ocupada por los humanos y un área inferior a la cual descienden las personas transformadas en bestias.

- Debido al movimiento que anima el cosmos, al mundo humano lo caracteriza la falta de estabilidad. Su existencia es pasajera y en buena medida depende de los ancianos, quienes con sus oraciones lo sostienen. Inestable por naturaleza, la hamaca también pende de lazos amarrados a bastoncillos que, por su denominación, forma y función, son asimilados a parientes de la tercera generación ascendente.

- Por último, mundo y hamaca son objeto de una ligera antropomorfización que coincide en su rasgo más importante. Uno de los extremos de ambos se describe como una columna vertebral: la Sierra Nevada en lo que respecta al espacio humano y la última hilera de la urdimbre en lo que se refiere a la hamaca. En ninguno de los dos casos, esta suerte de espinazo se asocia a un eje central que la divida en partes iguales. Por el contrario, se relaciona con uno periférico que, sin dejar de garantizar la unidad del conjunto, le otorga una forma asimétrica.

Ninguna de las coincidencias observadas parece obedecer a la preeminencia de uno de los dos órdenes desde el cual se proyectarían ciertos rasgos a otro que serviría de telón: de una cosmología rígidamente construida hacia un objeto que la simbolizaría, o bien de una hamaca omnipresente desde la infancia hacia un espacio vacío de significado. Más bien, parecerían ser el resultado de la aplicación de una misma serie de principios. A título de hipótesis puede sugerirse que ambos serían objetivaciones de un mismo esquema compartido e interiorizado que, sin movilizar un saber explícito, organizaría los conocimientos y dirigiría la acción en 
múltiples niveles: desde la apropiación del territorio y la experimentación del tiempo hasta el arte y la mitología de la hamaca.

Partiendo de sus rasgos más prominentes y sus expresiones más tangibles, a este esquema es posible otorgarle una forma gráfica. Siguiendo el consejo de Tim Ingold con el que se abrió este artículo (2007, p. 52), se trataría de convertir los hilos en trazos, y los trazos en hilos, con el fin de disolver y restituir superficies (Figura 14).

\section{FUTURO}

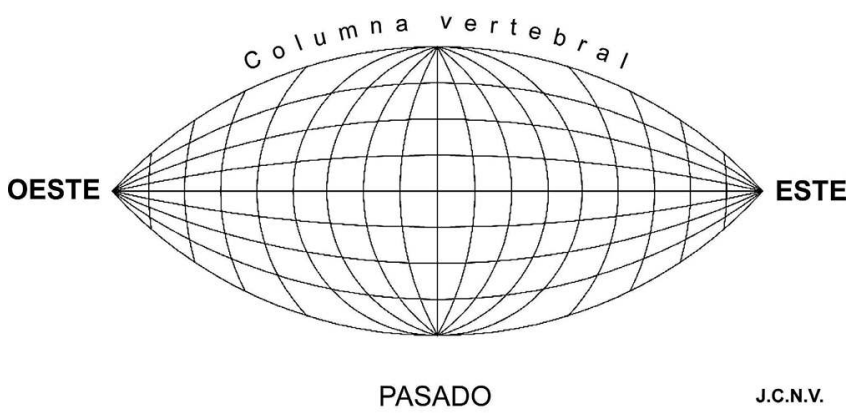

FIG. 14 - Modelo del cosmos.

Espacio y tiempo son inseparables y se cruzan en todos los puntos. La imagen central representa el espacio humano actual, explayado de este a oeste y oponiéndose a un arriba asociado al porvenir y a un abajo relacionado con el pasado. Su cuerpo oblongo se asemeja al de la hamaca, pero también podría hacerlo al de otras objetivaciones del mismo esquema. Entre estas pueden contarse el banco de dos patas (Brettes 1898, p. 469; Bolinder 1924, p. 212), o bien la base de las viviendas tradicionales (ibid., p. 206; Figura 15). Además, es idéntico al modelo del espacio fusiforme de los jivaros candoshis de la Alta Amazonía propuesto por Surrallés (2003, p. 97; Figura 16), para quienes la tierra también se extiende sobre un eje delimitado por dos polos opuestos. El caso ette, de hecho, debe ser visto como una confirmación empírica más de la pertinencia de un espacio indígena no euclidiano.

Como cualquier otro, el diagrama sugerido empobrece la realidad que intenta explicar. No obstante, sintetiza un complejo conjunto de principios cuya unidad y congruencia eran difíciles de entrever. Entre estos se cuentan el carácter bipolar, cóncavo y continente del mundo humano; la intrincada relación del espacio y el tiempo; y el movimiento descendente que marca el ritmo del devenir. Sobre él también pueden inscribirse ordenadamente un variado conjunto de prácticas y 

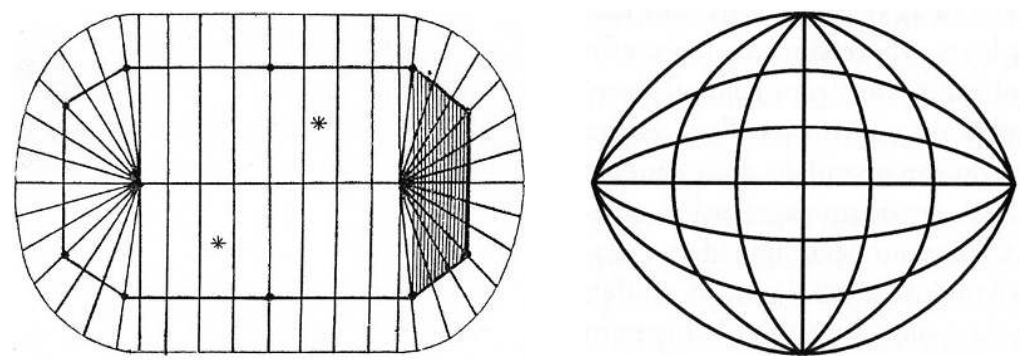

FIG. 15 y 16 - Plano de la casa chimila según Gustaf Bolinder (1924, p. 206) y geometría del espacio candoshi según Alexandre Surrallés (2003, p. 97). Cortesía de Alexandre Surrallés.

representaciones nativas que, en un principio, parecían independientes e irreductibles pero que en realidad forman un sistema coherente de oposiciones y correspondencias. Algunas de ellas pueden observarse en la siguiente tabla, susceptible de enriquecerse, pero suficiente para los intereses del presente texto (Figura 17).

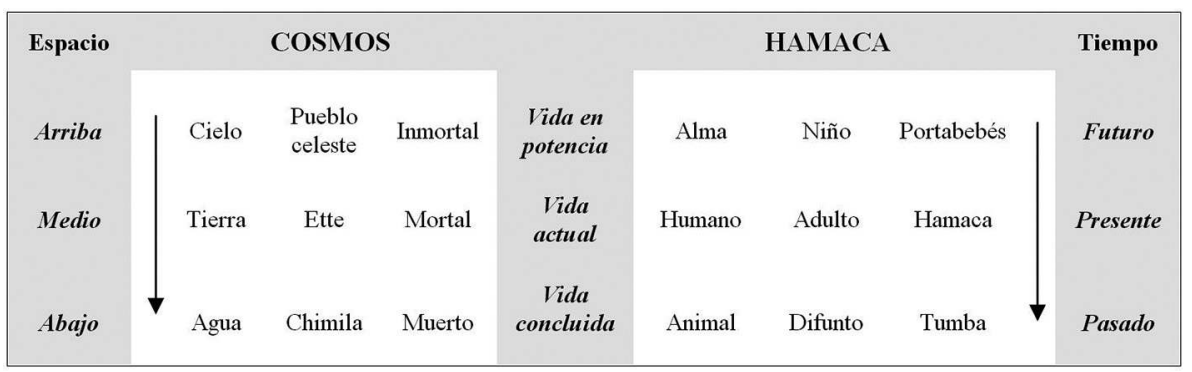

FIG. 17 - Correspondencias entre cosmos y hamaca.

Tres órdenes espacio-temporales definidos por la posición que ocupan respecto a los otros en un momento dado de un proceso de integración y desintegración. Aquel que pertenece a los humanos propiamente dichos, hombres y mujeres adultos, ocupa un lugar intermedio en todo sentido: entre las alturas celestes y las profundidades telúricas; entre una región que nunca será destruida y otra de la cual sólo quedan ruinas; entre un pueblo inmortal que desconoce la degradación del cuerpo y otro cuyos habitantes ya están muertos o han sido denigrados a vivir con cuerpos de animales; entre los humanos que acaban de ver la luz de la vida y aquellos para los que ésta se ha apagado definitivamente; entre un portabebés que reposa en lo alto asegurando que el alma permanezca en el cuerpo y una hamaca mortaja enterrada bajo la tierra, de 
la cual las almas salen para descansar en los confines del mundo, o bien convertirse en agresivas fieras; en suma, entre una vida en potencia que espera actualizarse y una vida concluida cuya memoria se borra paulatinamente. Acaso podría añadirse otra serie de oposiciones bien conocidas, a saber, la de los dominios divino, cultural y natural que, en el caso ette, no se enfrentarían sino, más bien, ilustrarían estados progresivos de un mismo y único proceso. *

* Manuscrit reçu en juin 2013, accepté pour publication en février 2014.

\section{Notas}

Estoy en deuda con todos los ette involucrados en la investigación y, en especial, con Samuel Granados Kraanti, Luisa Granados Diiñato, Felix Mendinueta Duutitu’, Narciso Puello y Joaquín Masias Jiintiyu. Algunas ideas del texto fueron presentadas en el Séminaire d'anthropologie américaniste dirigido por Isabelle Daillant y Bonnie Chaumeil, espacio en donde pude beneficiarme de los sugestivos comentarios de organizadores e invitados. Agradezco la enriquecedora lectura de Fabricio Cabrera, Marianne Cardale-Shrimpff, Sophie Desrosiers, Dimitri Karadimas, Marta Herrera, Roberto Pineda y Alexandre Surrallés. En la misma medida reconozco la labor de Magda Dziubinska, Andrea Leiva, Laura Murillo, Álvaro Santoyo, los miembros de la Fundación Ann Osborn, los integrantes del Taller de Investigación Umbra y el equipo del Journal de la Société des Américanistes. A Philippe Descola se le debo su gran apoyo moral e intelectual.

1. La información etnográfica que se presenta fue recogida entre 2003 y 2011 durante varios trabajos de campo en territorio ette. Un primer acercamiento de cinco meses tuvo lugar en 2003 y se efectuó en el marco de una maestría en antropología de la Universidad de los Andes. Una segunda fase más profunda de veintidós meses se realizó entre 2010 y 2012, estuvo financiada por la Universidad de los Andes y la Fundación Ann Osborn y se efectuó en el marco de un doctorado en la École des hautes études en sciences sociales.

2. Para la trascripción de la lengua ette se utilizó el alfabeto que la comunidad está tratando de implantar. La mayoría de consonantes y vocales se pronuncian igual que en castellano. Las excepciones son $\mid g /$, que es una palatal nasalizada, y $/ \mid l$, que es una irrupción glotal. La $|b /|$,$d / y / g /$ siempre se prenasalizan. (Niño Vargas 2009, pp. 78-79; Trillos Amaya 1996; Malone 1997).

3. Sobre la base de varios mitos recogidos en español, en un trabajo anterior se establecieron varias correspondencias entre accidentes geográficos y partes del cuerpo de la gran entidad femenina asociada a la tierra (Niño Vargas 2007, pp. 71-72, 293). Ninguna de estas asociaciones apareció en las entrevistas hechas en lengua ette.

4. Los ciclos de destrucción parecen alejar a los ette de los pueblos chibchas y acercarlos a algunos grupos mesoamericanos y amazónicos. Las coincidencias con la cosmología de los yukuna-matapí del noroeste amazónico son estrechas, pues en ambos casos se encuentra la imagen de un cosmos que se desploma (Reichel de von Hildebrand 1987, pp. 218-219). Una descripción más detallada al respecto se realizó anteriormente (Niño Vargas 2008).

5. Aunque la mayoría de las hamacas fabricadas por los ette son de algodón (Gossypium barbadense), algunos investigadores reportaron el uso de corteza vegetal (Brettes 1898, p. 465; Bolinder 1924, p. 211).

6. Reichel-Dolmatoff aseguró que la hamaca se confeccionaba con una sola madeja de hilo en patrón z y que la torsión inversa estaba restringida a algunas telas provenientes del Alto Ariguaní (1946, p. 113). Esta afirmación contrasta con lo notado por Cardale-Schrimpff, quien observó que dos tipos de hilo diferentes se usaban en la confección de las hamacas: uno delgado en patrón z y uno grueso en patrón s (1972, pp. 153 y 171). Ninguna de estas observaciones coincide exactamente con lo observado hoy día, pero la oposición entre dos hilos sigue presente. 
7. Reichel-Dolmatoff notó que no había nudos en la hamaca y que las tramas colgaban libres en los extremos (1946, p. 114). Esta descripción no coincide con lo observado por Cardale-Shrimpff (1972, p. 170). Las tramas sueltas tampoco pueden observarse en las hamacas que ilustró Brettes en el siglo XIX (1898, pp. 463 y 476).

8. Las largas cadenas de asociaciones que unen a la cultura material y el cuerpo humano, tan comunes entre los grupos de la familia chibcha, son raras entre los ette. Los pueblos de la Sierra Nevada de Santa Marta, por ejemplo, aseguran que la hamaca puede ser vista como una placenta y, siguiendo esta asociación, como una casa (Reichel-Dolmatoff 1985, vol. 1, p. 240). Una idea similar se encuentra entre los urarina de la Amazonía peruana (Walker 2009, p. 89). Este tipo de analogías son negadas explícitamente por los ette quienes, adicionalmente, son bastante reservados a la hora de hablar de la sexualidad y reproducción humanas.

9. Aunque en una forma distinta a la expuesta, vale la pena anotar que es un procedimiento común entre las poblaciones amerindias dotar de significación a la altura de la hamaca, en especial, en el dominio del género y la edad (Désiré 1994, pp. 119-120; Pinton 1965, pp. 266-267).

\section{REFERENCIAS CITADAS}

\section{BOLINDER Gustaf}

1924 «Die letzten Chimila-Indianer», YMER. Svenska Sällskapet för Antropologi och Geografi, 44 (2), pp. 200-228.

BRETTES Joseph de

1898 "Chez les Indiens du nord de la Colombie. Six ans d'explorations », Le Tour du monde, 4 (n.s.), pp. 61-96, 433-480.

CARDAle-SCHRIMPFF Marianne

1972 Techniques of hand-weaving and allied arts in Colombia, tesis doctoral, University of Oxford, Oxford.

Carsten Janet y Stephen Hugh-Jones (eds.)

1995 About the house. Lévi-Strauss and beyond, Cambridge University Press, Cambridge.

DaILlant Isabelle

2003 Sens dessus dessous. Organisation sociale et spatiale des Chimane d'Amazonie bolivienne, Société d'ethnologie, col. "Recherches américaines », Nanterre.

DÉSIRÉ Guy

1994 «Le mouvement des hamacs. Modèles symboliques et modèle social des Indiens tikuna ", Journal de la Société des Américanistes, 80, pp. 113-143.

ERIKSON Philippe

2001 "Myth and material culture: Matis blowguns, palm trees, and ancestor spirits », in Laura Rival y Neil L. Whitehead (eds.), Beyond the visible and the material: the amerindianization of society in the work of Peter Rivière, Oxford University Press, Oxford, pp. 101-121.

\section{Guss David M.}

1989 To weave and sing. Art, symbol, and narrative in the South American rain forest, University of California Press, Berkeley. 
HALL Ingrid

2012 «Labourer la terre, tisser la vie. Éclats d'analogies dans les Andes sudpéruviennes », Journal de la Société des Américanistes, 98 (1), pp. 101-131.

Herrera Ángel Marta

2002 Ordenar para controlar, Instituto Colombiano de Antropología e Historia, Bogotá.

HuGH-JonEs Christine

1979 From the Milk River: spatial and temporal process in Northwest Amazonia, Cambridge University Press, Cambridge.

INGOLD Tim

2007 Lines. A brief history, Routledge, Londres/Nueva York.

KARADIMAS Dimitri

2005 La raison du corps. Idéologie du corps et représentations de l'environnement chez les Miraña d'Amazonie colombienne, Peeters, col. « Langues et sociétés d'Amérique traditionnelle »10, París/Lovaina.

LitTLEFIELD Alice

1976 La industria de las hamacas en Yucatán, Instituto Nacional Indigenista, col. « SEP INI » 52, México.

MaLONE Terrell

1997 «Mora, minimal foot and segmental phonology in Chimila », Estudios de lingüística chibcha, 16, pp. 19-69.

2004 «Classifiers in Chimila (Chibchan)», Schprachtypologie und Universalienforschung, 57, pp. 144-201.

MoRALEs Gómez Jorge

1993 «Fauna, trabajo y enfermedad entre los cuna », in François Correa (ed.), La selva humanizada: Ecología alternativa en el trópico húmedo colombiano, Instituto Colombiano de Antropología, Bogotá, pp. 171-191.

NiÑo VARGAS Juan Camilo

2006 "Oniromancia y perspectiva entre los ette del norte de Colombia », Maguaré, 20, pp. 13-37.

2007 Ooyoriyasa. Cosmología e interpretación onírica entre los ette del norte de Colombia, Universidad de los Andes, Bogotá.

2008 «Ciclos de destrucción y regeneración. Experiencia histórica entre los ette del norte de Colombia », Historia crítica, 35, pp. 106-129.

2009 «Sistema de clases y principio de paridad. Observaciones lingüísticas y etnográficas sobre el sistema de numeración ette », Estudios de lingüística chibcha, 28, pp. 75-108.

\section{NORDENSKIÖLD Erland}

$1920 \quad$ The changes in the material culture of two Indians tribes under the influence of new surroundings, Elanders Boktryckeri Aktiebolag, col. «Comparative ethnographical studies »2, Gotemburgo. 
O'NEALE Lila M.

1963 "Weaving », in Julian H. Steward (ed.), Handbook of South American Indians, vol. 5, Cooper Square Publisher, Nueva York, pp. 97-138.

Osborn Ann

1995 Las cuatro estaciones. Mitología y estructura social entre los u’wa, Banco de la República/Museo del Oro, Bogotá.

PINTON Solange

1965 «Les Bari », Journal de la Société des Américanistes, 54, pp. 247-333.

QueIXaLos Francisco

1985 «L'orientation spatiale dans la grammaire sikuani », Journal de la Société des Américanistes, 71, pp. 115-128.

REICHEL DE VON HILDEBRAND Elizabeth

1987 «Astronomía yukuna-matapí », in Jorge Arias de Greiff y Elizabeth Reichel de Von Hildebrand (eds.), Etno-astronomías americanas, Universidad Nacional de Colombia, Bogotá, pp. 193-232.

\section{Reichel-Dolmatoff Gerardo}

1946 «Etnografía chimila », Boletín de arqueología (Bogotá), 2 (2), pp. 95-155.

1978 "The loom of life: a Kogi principle of integration », Journal of Latin American Lore, 4 (1), pp. 5-27.

1985 Los kogi: una tribu de la Sierra Nevada de Santa Marta, Colombia, 2 vols., Procultura, Bogotá.

Rival Laura

1996 «Blowpipes and spears: The social significance of Huaroni technological choices ", in Philippe Descola y Gísli Pàlsson (eds.), Nature and society: anthropological perspectives, Routledge, Londres, pp. 145-164.

\section{SCHAEFER Stacy}

1989 «The loom and time in the Huichol world », Journal of Latin American Lore, 15 (2), pp. 179-194.

SeILER-BALdinger Annemarie

1979 «Hängematten-Kunst: textile Ausdrucksform bei Yagua- und TicunaIndianern Nordwest-Amazoniens ", Verhandlugen der Naturforschenden Gesellschaft in Basel, 90, pp. 59-130.

SuRrallÉs Alexandre

2003 Au cœur du sens: perception, affectivité, action chez les Candoshi, CNRS Éditions/Éditions de la Maison des sciences de l'homme, col. « Chemins de l'ethnologie », París.

Trillos Amaya María

1996 Categorías gramaticales del ette taara: lengua de las chimilas, Universidad de los Andes, Bogotá. 


\section{UriBe ToBón Carlos Alberto}

1977 «La rebelión chimila en la provincia de Santa Marta », Estudios andinos, 13, pp. 113-165.

Van Velthem Lucia HussaK

2003 O belo é a fera. A estética da produção e da predação entre os Wayana, Museo Nacional de Etnologia, Lisboa.

\section{WALKER Harry}

2009 "Baby hammocks and stone bowls », in Fernando Santos-Granero (ed.), The occult life of things, University of Arizona Press, Tucson, pp. 81-102.

WIEDEMANN Inga

1979 «Brazilian Hammocks », Zeitschrift für Ethnologie, 104, pp. 105-133. 